\title{
Questões em torno da formação inicial de professores
}

\author{
Cláudio Lúcio Mendes ${ }^{1}$ \\ Luana de Cássia Martins Rodrigues ${ }^{2}$
}

\section{Resumo}

Neste texto, abordamos seis questões contemporâneas sobre a formação inicial de professores. Tais questões foram levantadas, prioritariamente, com base em parte da literatura contemporânea sobre o assunto e em diálogo metodológico com as proposições foucaultianas sobre a arte de governo. Analiticamente, tratamos da formação docente como uma arena de luta contemporânea; do lugar que ocupa a licenciatura nas instituições de Ensino Superior brasileiras; do novo tipo de aluno que está chegando às licenciaturas; da necessidade de aproximação entre instituições de Ensino Superior / escolas públicas municipais e estaduais; da organização do currículo de formação e o investimento na formação inicial advindos de políticas contemporâneas. Concluímos que o sujeito é um produto - e, ao mesmo tempo, produtor - das práticas sociais, entendidas como aquelas conexões que nos ligam a outros humanos, a saberes e a relações de poder que nos rodeiam, constituindo a nós como tipos específicos de alunos e professores.

Palavras-Chave: formação de inicial de professores; governo de Estado; Foucault; políticas públicas.

1 Doutor em Educação pela Universidade Federal do Rio Grande do Sul (UFRGS), Brasil. Professor da Universidade Federal de Ouro Preto (UFOP), Brasil. claudio.ufop@yahoo.com.br

2 Mestranda em Educação pela UFOP. luanacassiar@yahoo.com.br 


\title{
Issues on teacher initial education
}

\begin{abstract}
In this paper, we address six contemporary issues on teachers' initial education. These issues were raised, primarily, based on part of the contemporary literature on the subject and on a methodological dialogue with Foucault's propositions about the art of government. Analytically, we address: the teacher education as an arena of contemporary struggle; the place occupied in higher education degree by the brazilian institutions; the new type of student who is coming to undergraduate courses; the necessity for closer ties between higher education institutions / public schools; the organization of the training curriculum and the investment in the initial formation arising from contemporary political. We conclude that the subject is a product - and, at the same time the one that produces the social practices, understood as those connections that link us to other human, the knowledge and the power relations that surround us, constituting us as specific types of students and teachers.
\end{abstract}

Keywords: teachers' initial education; State government; Foucault; public policies.

\section{Introdução}

Ser professor é uma das profissões mais complexas que conhecemos no contexto da arte de governo contemporânea. Estamos inseridos em um intenso campo de relações de poder. Planejar aulas, dar aulas: refletir e ser questionado sobre o planejamento e as aulas dadas... Conviver com os colegas, alunos, funcionários, pais: ponderar e problematizar essa convivência... Trabalhar com o currículo, a didática, os métodos: reconsiderar esse trabalho... Fazer pesquisas, buscar informações, atualizar-se constantemente: observar o já observado, reviver o vivido, arriscar-se no desconhecido. Por um ponto de vista, são atividades que não se encerram nas instituições escolares. Muitas vezes, as levamos para casa e, com certeza, ficam em nossas cabeças e nos acompanham 
em muitos lugares. E, ao mesmo tempo, são entendidas como técnicas de dominação e de si, constituindo maneiras de pensar e agir a perpassar os professores, com certeza, com diferentes efeitos na conduta da conduta.

A fim de atender a objetivos como, por exemplo, formar trabalhadores para o mercado, os professores têm se intensificado como um dos grupos ocupacionais mais importantes e uma das peças principais para a economia das sociedades (GATTI; SÁ BARRETTO, 2009). Assim, quanto maior é a expectativa sobre o professor, quanto mais plural se deseja a sua atuação, maior será a responsabilidade de sua formação inicial. Corroborando e ampliando esse argumento, a formação inicial, cada vez mais, vem merecendo atenção especial, pois tanto para o governo de Estado (que precisa dar conta da educação de sua população) como para o governo de si (pois cada sujeito deve fazer e participar de escolhas teóricas, culturais, econômicas, de estilo de vida etc. atreladas aos caminhos profissionais trilhados) é um momento significativo na vida de cada docente (REALI; FERREIRA, 2005).

Problematizar essas e outras questões em torno do trabalho docente passa também, em nossa opinião, por abordar o significado da formação inicial de professores no Brasil contemporaneamente dentro de uma racionalidade de governo. Um professor não é formado somente quando entra para a sala de aula ou em uma instituição, como profissional. Ele começa a ser formado bem antes, em especial no período da graduação, em cursos de licenciatura, tendo como orientação para os cursos as políticas curriculares e educacionais propostas. Em torno da formação inicial, igualmente, circulam várias questões. Neste texto, descreveremos algumas dessas questões levantadas, prioritariamente, com base em parte da literatura contemporânea sobre o assunto e em diálogo metodológico com as proposições foucaultianas sobre governo.

Como resultado desse diálogo entre a literatura contemporânea sobre formação inicial de professores e a arte de governo em Foucault, expomos seis questões/problemas relativos à formação inicial. No entanto, antes delas, apresentaremos as questões de método a orientar nossas problematizações. Em seguida, como primeira questão analítica, trataremos da formação docente como uma arena de luta contemporânea. 
Em sequência, descreveremos o lugar que ocupa a licenciatura nas instituições de Ensino Superior brasileiras; que um novo tipo de aluno está chegando às licenciaturas; a necessidade de aproximação entre instituições de Ensino Superior / escolas públicas municipais e estaduais; a organização do currículo de formação e o investimento na formação inicial advindos de políticas contemporâneas.

\section{Questões de método}

No decorrer do século XVI até meados do século XVIII, foi tomando forma uma nova lógica de racionalidade governamental, configurada sua estrutura como a que vivemos hoje a partir do século XIX. A produção dos conflitos de conduta (moral, ética, legal, social) deixa de estar tanto no campo das instituições religiosas e passa a estar mais no contexto das instituições políticas. Para Foucault (2008a; 2008b), nesse período é possível verificar a passagem de uma arte de governo baseada nas virtudes tradicionais e na habilidade humana para outra cujos princípios de conduta são próprios dos Estados modernos e contemporâneos e suas instituições.

Ao constatar esse novo momento na história ocidental, Foucault desenvolve a noção de mentalidade (ou racionalidade) de governo (FOUCAULT, 2004; 2008a; 2008b). Essa racionalização do exercício de governo tem como objetivo não apenas a manutenção de um território, mas sim (e em especial) o governo dos homens. O Estado, presente na vida de todos os indivíduos, deve cuidar de sua população: não se governa, no âmago, um conjunto de instituições, um território ou uma estrutura política - "quem é governado são sempre pessoas, são homens, são indivíduos ou coletividades" (FOUCAULT, 2008b, p. 164), especialmente focado no exercício para uma soberania política.

Ainda sobre o método de se pensar a arte de governar, Foucault (2008a; 2008b) fala sobre a existência de uma continuidade ascendente e descendente. Em relação à continuidade ascendente, aquele que quer governar o Estado deveria antes governar a sua família, seus bens e a si mesmo. Na continuidade descendente, o Estado deve ser bem governado, propondo - a todos e a cada um - condutas da conduta que produzam efeitos para e sobre a coletividade. Para ter sucesso, a mesma 
racionalidade deve constituir e perpassar práticas do governo de Estado (das organizações estatais sobre a coletividade dos indivíduos de uma população), do governo dos outros (de sujeitos sobre outros sujeitos) e do governo de si (do sujeito sobre si mesmo). Nessas três facetas de governo, encontram-se pontos de contato e sobreposições entre os procedimentos de conhecimento: 1) do que é o Estado para a boa conduta da população; 2) do que é o outro para conduzir-lhe a conduta; e 3) do que somos nós mesmos para autoconduzirmos (RABINOW; ROSE, 2006).

Além disso, por um lado, as discussões sobre Estado e governo são unânimes em afirmar a dificuldade em diferenciá-los (GOZZI, 1998; LEVI, 1998). Em consequência, diferenciar o que seria política de Estado de política de governo é igualmente difícil. Por outro lado, "nada, portanto, de interrogar os universais utilizando como método crítico a história, mas partir da decisão da inexistência dos universais para indagar que história se pode fazer" (FOUCAULT, 2008, p. 5-6) e pensar sobre Estado e governo. Em dedução, Foucault argumenta que as políticas de Estado passam por uma racionalidade de governar que dá legitimidade ao funcionamento do Estado para o governo da conduta de diferentes formas, em diversos momentos históricos.

Nesse sentido, afasta-se de noções idealizadas de Estado para afirmar que "o Estado nada mais é que uma peripécia do governo, e não o governo que é um instrumento do Estado. Ou, em todo caso, o Estado é uma peripécia da mentalidade de governo" (FOUCAULT, 2008a, p. 331) historicamente localizada. Em síntese, "governar racionalmente porque há um Estado e para que haja um Estado" (FOUCAULT, 2008a, p. 332). Podemos deduzir daí que uma política para se tornar de Estado dependerá mais da racionalidade de governo a lhe dar sustentação do que das leis a lhes darem base formal. Argumentamos, nesse sentido, que determinada mentalidade neoliberal de governo vem pautando as políticas do Estado brasileiro - tornando-se, muitas vezes, políticas de Estado - desde o fim dos governos militares, no final dos anos 80, até o governo de Dilma Rousseff (2010-2014).

Chegamos, então, em outro aspecto de método: como estamos entendendo o neoliberalismo? Como uma racionalidade histórica, 
temporalmente localizável, que toma a sua configuração atual a partir do fim da Segunda Guerra Mundial em vários países do ocidente (levando em conta suas discussões de maior repercussão na Alemanha e nos EUA), tratandose "na verdade de uma nova programação da mentalidade de governo liberal". Ao mesmo tempo apoiando-se no liberalismo clássico e criticando-o, propõe "uma reorganização [...] que, mais uma vez, não pergunta ao Estado que liberdade você vai dar à economia, mas pergunta à economia: como a sua liberdade pode ter uma função e um papel de estatização, no sentido de que isso permitira fundar efetivamente a legitimidade de um Estado" (FOUCAULT, 2008a, p. 127) a favor de relações livres de mercado, competitivas e formalizadas legalmente? Em síntese, a estruturação de um Estado gerencial no contexto das relações econômicas globalizadas.

Abordando essa mentalidade de governo a produzir efeitos sobre todos e em cada um, Foucault (2008b) aponta algumas instâncias nas quais ocorrem, descrevendo o funcionamento e os efeitos da "arte de governar". Em dedução, uma dessas instâncias, obviamente, é a escola e todo o conjunto de mecanismos e especialistas que são empregados para fazê-la funcionar. Neste texto, as seis questões descritas em torno da formação inicial de professores são consideradas, além de outras coisas, expressões de uma mentalidade de governo, imbricadas em técnicas de vigilância e técnicas de controle - técnicas empregadas tanto para a conduta de outros por outros e pelo Estado, como para a conduta de si - voltadas para o governo contínuo e permanente dos indivíduos. Assim, na análise da formação inicial, entendemos o Estado não como algo universal ou que possua uma essência. Buscamos compreendê-lo como efeito de práticas de governo e de eventos históricos pontuais e, no caso deste texto, de eventos contemporâneos.

Com o olhar da racionalidade de governo a nos pautar, para identificar as questões em torno da formação inicial de professores, realizamos uma revisão bibliográfica capturando os trabalhos apresentados nas Reuniões anuais da ANPED, dando foco aos artigos do GT de formação de professores, a partir da $23^{\text {a }}$ Reunião Anual ${ }^{3}$. Buscamos, da mesma

3 Disponível em: <http://www.anped.org.br/internas/ver/reunioes-anuais>. Acessos de 25 jul. 2012 a 02 set. 2013. 
maneira, artigos publicados em periódicos nacionais a tratar do assunto. Por último, trabalhamos com livros e pesquisas que, sabíamos, tratavam das discussões em torno da formação de professores, dando maior atenção aos argumentos apresentados em torno da formação inicial. Primeiramente, lemos todos os resumos dos artigos encontrados no site da ANPED e nos periódicos consultados a tratarem do nosso termo de busca (formação inicial de professores). Selecionados os artigos, os livros e as pesquisas e resenhamos todos eles. Em um terceiro momento, buscamos as questões a se repetirem nos textos com mais constância e que, de uma maneira ou de outra, tinham mais repercussão e mais necessidade de problematização, segundo os autores. A leitura e a resenha dos livros ajudaram-nos a consolidar as seis questões tratadas aqui. Obviamente, por motivo de espaço, nem todos os textos lidos são citados. Demos atenção para aqueles que, de uma maneira ou de outra, sintetizam os argumentos que queremos expor.

Nos estudos feitos para a elaboração deste artigo, tivemos clareza que "há um consenso de que as propostas tradicionais de formação e de carreira já não são suficientes. Mas há também fortes evidências de que não é simples determinar quais são as mudanças adequadas e muito menos colocá-las em prática" (CAMPOS, 2006, p. 192). Não tentamos aqui nem uma coisa nem outra, mas sim, conscientes da ambiguidade entre as coisas a serem superadas e a dificuldade em superá-las, problematizar algumas questões em torno da formação docente, no contexto da arte de governar contemporânea. Essa opção de método implicou em consultar determinadas fontes bibliográficas com a meta de se obter uma melhor compreensão dos processos de formação de professores, bem como pensar a licenciatura como uma arena política de luta.

\subsection{Primeira questão: a arena contemporânea de formação docente}

O marco na inserção da racionalidade de governo neoliberal no Brasil pode ser visto com a reforma do Estado na década de 1990. Como mostram Malanchen e Vieira (2006), o neoliberalismo foi adotado como política de Estado a partir do governo do presidente Fernando Collor 
de Mello (1990-1992). Simultaneamente à reforma do Estado, no Brasil, iniciou-se a reforma educacional que emergiu no governo do presidente Itamar Franco (1992-1994). Essa emergência estava em concordância com ajustes firmados em conferências, como, por exemplo, a Conferência de Jomtien, em 1990, na Tailândia, na qual se enfatizou o direito de todos à educação básica. Malanchen e Vieira (2006) afirmam que a Conferência de Jomtien funcionou como espaço de difusão das políticas internacionais para a educação, e o governo brasileiro intencionou cumprir os compromissos firmados nessa conferência por meio do Plano Decenal de Educação para Todos, incluindo aí a formação inicial de professores. Para se localizar especificamente a trajetória sobre a formação inicial de professores, tanto no âmbito da lei como no âmbito dos procedimentos de Estado que a viabilizam, se faz necessária uma breve discussão sobre as políticas educacionais dos anos de 1990.

A agenda dos organismos internacionais de financiamento (Banco Mundial, FMI etc.) apontou para a crise da educação como uma crise de eficiência, eficácia e produtividade do sistema - na verdade, essa seria a tríade básica das críticas às instituições de Estado feitas com base em perspectivas neoliberais (BRESSER-PEREIRA, 2000). Com efeito, as reformas educacionais implementadas no Brasil foram construídas por procedimentos a atribuírem, como aspecto central, a crise da educação à má formação de professores - profissionais ineficientes, ineficazes e improdutivos, dentro da proposta de um Estado gerencial. As críticas realizadas pelos organismos internacionais serviram de base para o consenso da necessidade da reforma educacional, centrando atenção na formação de professores.

Ao considerar as mudanças que ocorreram com as reformas nos anos 1990, Oliveira (2009, p. 201) observa que de "políticas inicialmente orientadas ao atendimento universal, passou-se a persecução de públicos alvos específicos". Com essa lógica, o governo Fernando Henrique Cardoso (1995-2002) fortaleceu, como meio orientador das políticas sociais, o recurso à racionalidade neoliberal de governo. Esperava-se a ruptura com essa lógica no governo de Luís Inácio Lula da Silva (20032010) - pelo menos era essa a esperança dos movimentos sociais que o 
apoiaram na eleição para o primeiro mandato. Entretanto, ao analisar o seu primeiro mandato, Oliveira (2009) considera que ocorreram mais permanências do que rupturas. Talvez isso evidencie como o processo de criação de políticas pode ser modelado de diversas maneiras, realmente como uma arena política em disputa, tendo como base uma mesma racionalidade neoliberal de governo.

Observa-se que as políticas de formação de professores nesse período foram redesenhadas pelo Estado com o objetivo de ajustar o professor e a formação docente às demandas do mercado de trabalho e aos investimentos em capital humano (GATTI; SÁ BARRETO, 2009). As reformas desse período buscam traduzir as demandas colocadas pela racionalização do Estado. Racionalização essa pautada em uma legitimidade da economia a determinar os aspectos legais, formais e de ajuste de conduta para maior eficiência do humano, tornando esse humano foco também (e especial) de investimento e controle (FOUCAULT, 2008b).

A orientação das reformas no Brasil nos anos 1990 era justificada pela necessidade da modernização do país (e de sua população) econômica, política e gerencialmente. A descentralização administrativa, financeira e pedagógica - tendo como eixo a lógica do Estado gerencial a propor o funcionamento das instituições de Estado de maneira correlata às instituições de mercado - foi a grande marca dessas reformas, resultando no repasse de responsabilidades para todos os entes do Estado. Oliveira (2009) observa que ao mesmo tempo em que se descentralizam as ações de implantação, são postas em ação novas formas de controle, conduta e vigilância. Nesse sentido, certa racionalidade de governar oferece espaço para os comportamentos individuais e de produção - com o mínimo de atuação do Estado sobre os efeitos das relações de mercado -, porém, mantém forte vigilância sobre esses comportamentos para assegurar que os mesmos desempenhem-se de maneira conveniente - com o máximo de atuação formalizada do Estado sobre a conduta das populações (FOUCAULT, 2008b).

Em 1996, as instituições formadoras e os cursos de formação de professores tiveram que rever suas propostas curriculares a partir das 
alterações promovidas com a publicação da LDB. Com essa lei, o Instituto Superior de Educação, ao assumir a formação inicial e continuada dos professores da educação básica, emergiria como o novo lócus de formação de professores. Os institutos responsáveis pela formação dos professores - conforme o art. 63, incisos I, II e III, da Lei n 9.394, de 20 dezembro de 1996 - tinham como tarefa manter cursos formadores de profissionais para a educação básica, propiciar formação adequada para portadores de diplomas de educação superior que almejam atuar na educação básica e programas de educação continuada para os profissionais de educação, nos diversos níveis.

Lima (2004) afirma que essa lei retrocede ao localizar a formação de professores nos Institutos Superiores de Educação, já que no Brasil esse tipo de instituição localizar-se-ia entre as mais simples. Questiona, ainda, se essa localização é porque profissionais bem formados exigem profissionalização decente e respeitável, profissionalização que supostamente localizar-se-ia em tais institutos. Isso, por sua vez, coloca à prova como aceitar professores, que, apesar de receberem o mesmo título, formam-se em espaços tão distintos. Outra observação refere-se ao fato das exigências do MEC quanto à composição de mestres e doutores no corpo docente dos diferentes espaços de formação. A mesma autora destaca que a Resolução CNE/CP n 1, de 30 de setembro de 1999, determina para o corpo docente dos Institutos Superiores de Educação apenas $10 \%$ de mestres ou doutores, enquanto a exigência para as universidades cresce a ponto de atingir $75 \%$.

A criação desses institutos não discutiu os motivos pelos quais a universidade não conseguiu levar a bom termo essa formação profissional e, provavelmente, os Institutos também não conseguiriam por motivos similares (SEVERINO, 2008). As razões de sua criação foram outras. Desse modo, a localização da formação de professores nos Institutos indicou o desprestígio que a racionalidade de governo contemporânea confere à educação e a seus profissionais. Mesmo que a proposição dos Institutos Superiores de Educação não tenha repercutido a ponto de se tornarem centros de formação, a diversificação da oferta de cursos de formação de professores (Cursos Normais Superiores, de Pedagogia e 
de licenciatura) expandiu-se principalmente em instituições privadas. De acordo com Maciel e Neto (2004), a ampliação da iniciativa privada é vista como um dos pilares que sustentam o pressuposto básico da racionalidade neoliberal para um Estado gerencial, isso é, a criação de um mercado educacional livre. Para Freitas (2007), essa oferta desenvolveuse, sobremaneira, em instituições sem compromisso com a formação, com o objetivo de gerar lucros no cenário das relações de mercado.

A necessidade de regulação no campo da educação e da formação de professores é uma das características essenciais na redefinição do papel do Estado (FREITAS, 2007). A aprovação da atual LDB representou o marco contemporâneo da formalização legal de certa mentalidade de governo nas políticas educacionais. Com essa Lei, por exemplo, atribui-se a todos os entes da federação (Municípios, Estados, Distrito Federal e União) a responsabilidade de formação para os professores em exercício. Contudo, como argumentamos, tal formalização não garantiu de imediato o exercício de tal mentalidade. Foi no final do primeiro e, com força concentrada, no segundo mandato do governo Lula que procedimentos deram concretude a essa política de Estado, no âmbito de seus entes, por meio de várias leis, ações e programas ${ }^{4}$.

Nesse sentido, a Coordenação de Aperfeiçoamento de Pessoal de Nível Superior (CAPES) surge como agência reguladora da formação de professores durante o segundo mandado de Lula. Antes essa formação era uma das prioridades do MEC. Mas, em 2007, com a Lei $\mathrm{n}^{\mathrm{0}} 11.502$, de 11 de julho de 2007, essa responsabilidade foi atribuída à CAPES, até ali responsável pelo gerenciamento dos cursos de pós-graduação e a formação de professores para o Ensino Superior.

De acordo com o art. $2^{\circ}$ do estatuto da CAPES, aprovado por meio do Decreto $n^{0}$ 7.692, de 2 de março de 2012, essa coordenação tem por

\footnotetext{
4 Ficou localizada na CAPES a efervescência dos programas propostos a partir do final do primeiro governo Lula. No ano de 2005, temos o Programa de Formação Inicial para Professores em Exercício na Educação Infantil (PROINFANTIL) e o Programa de Formação Inicial para Professores dos Ensinos Fundamental e Médio (PRÓ-Licenciatura). No ano de 2006, o Programa de Consolidação das Licenciaturas (PRODOCÊNCIA) e a Universidade Aberta do Brasil (UAB). Em 2007, criou-se o Programa Institucional de Bolsa de Iniciação à Docência (PIBID). Não obstante, em 2009, o Ministério da Educação lançou uma ação estratégica denominada Plano Nacional de Formação de Professores da Educação Básica (PARFOR). Posteriormente, no âmbito da CAPES, em 2010, elaborou-se o programa denominado Licenciaturas Internacionais.
} 
finalidade subsidiar o MEC na formulação de políticas e desenvolvimento de atividades de suporte à formação de profissionais de magistério para a educação básica e superior. No âmbito da educação superior, a finalidade da CAPES é subsidiar a formulação de políticas para pósgraduação. Relativo à educação básica, intenciona-se induzir e fomentar a formação inicial e continuada de profissionais do magistério. A CAPES apresenta como preferência o ensino presencial para a formação inicial, mas deixa claro que na formação continuada seprivilegiam tecnologias de educação à distância. Contudo, a implantação de um sistema de avaliação semelhante ao adotado para a pós-graduação é, para Freitas (2007), um objetivo central dessa transferência de responsabilidade, dentro da lógica do Estado gerencial.

A formação continuada administrada pela CAPES, por meio da educação à distância, é atualmente o centro da política de formação em serviço (FREITAS, 2007). Para Libâneo (2008), o governo do presidente Lula é mais um governo que não investiu em um sistema articulado de formação inicial de professores com uma sólida formação cultural e científica em cursos regulares nas instituições de ensino e em programas de formação continuada nas situações de trabalho. Com efeito, a educação a distância é um dos elementos cruciais a constituir as estratégias atuais em torno da formação de professores como uma arena de luta, pela força política e econômica que adquiriu, por um lado, e pelas críticas recebidas por parte de vários estudiosos e entidades representativas de professores e pesquisadores, por outro.

Não temos dúvida que o investimento na educação a distância vem se efetivando dos anos 2000 para cá. Mas, com certeza, nenhuma política educacional no Brasil investiu para tentar equilibrar outra relação: a das licenciaturas com os bacharelados nas instituições de Ensino Superior.

\subsection{Segunda questão: o lugar que ocupa a licenciatura nas instituições brasileiras}

O ensino e a formação para a docência nas Instituições de Ensino Superior (IES) no Brasil ocupam lugar secundário dentro de suas estruturas. As prioridades seriam as pesquisas. Inclusive, são os 
professores pesquisadores aqueles que obtêm maior destaque e respeito dentro do meio acadêmico. Ensino e pesquisa fazem parte de uma racionalidade de Estado a colocar essas duas funções das IES em desequilíbrio (MENDES, 1999).

Daí, temos uma repercussão imediata: o maior status obtido pelo bacharelado nos cursos de graduação em comparação à licenciatura é consequência da ligação histórica do primeiro com a pesquisa e com as políticas de Estado para eficiência e produtividade. Conclui-se que parte da dicotomia existente entre as duas formações se baseia no produto que cada uma oferece no meio acadêmico. $\mathrm{O}$ bacharelado apresenta um produto de "maior" valor de mercado, a pesquisa; a licenciatura, um produto de "menor" valor, a docência. Constata-se, nas universidades brasileiras, que o bacharelado é mais valorizado por estar ligado à pesquisa, enquanto a licenciatura apresenta menos status por trabalhar com a formação de professores (SANTOS, 1997; PRUDENTE, 2009).

Quando olhamos para o trabalho docente, percebemos a continuidade em "privilegiar-se a componente de produção de investigação científica (número e natureza dos projetos financiados, internacionalização, número e impacto de publicações etc.)" (ESTEVES, 2012, p. 24), critérios que, quando empregados nas licenciaturas, são para tê-las como um tema de pesquisa, não como um campo a produzir um conhecimento praticável. Evidencia-se que "as preocupações com o investimento dos docentes nos processos de ensino-aprendizagem e de formação, e no serviço de extensão à comunidade, sendo hoje maiores, continuam a ser claramente secundários" (ESTEVES, 2012, p. 24).

Isso acarretou historicamente e acarreta contemporaneamente alguns problemas graves. Como "as funções de pesquisa carregam maior valor agregado na representação sobre o perfil docente" e sobre a importância da docência e da pesquisa no mundo acadêmico, tais funções repercutem sobre a "formação[,] a prática pedagógica" (CUNHA, 2002, p. 46) e as políticas universitárias relacionadas aos licenciandos e ao trabalho dos professores universitários. Até há pouco tempo, as bolsas ofertadas pelos órgãos de fomento eram essencialmente orientadas para professores pesquisadores. De 2007 para cá, com programas como o Programa 
Institucional de Bolsas de Iniciação à Docência (PIBID/CAPES), algumas bolsas para atuação na formação inicial têm surgido.

Em relação aos professores, a menor importância política daqueles que tratam da licenciatura, dentro da burocracia universitária, acarreta limitações. Isso cria um círculo vicioso em torno da licenciatura, dificultando sua discussão de maneira profunda e por toda a comunidade universitária. Também há problemas com financiamento. Para os cursos de licenciatura circula menos dinheiro, sendo suas ações (como promover um evento que trate da formação inicial, por exemplo) dificultadas. Iniciativas têm sido criadas para superar isso. Marques e Pereira (2002) apontam que "algumas instituições de ensino superior instalaram, no início da década de 1990, fóruns permanentes de discussão e alguns também de deliberação a respeito da problemática das licenciaturas". Sabemos que em algumas instituições eles funcionam; em outras, tornaram-se estruturas esquecidas. No entanto, de qualquer forma, "esses fóruns das licenciaturas procuraram discutir os modelos dos cursos de formação de professores em vigor nas universidades" (p. 179-180).

Em relação aos alunos das licenciaturas, nota-se a evasão de muitos deles que, após cursarem alguns períodos, migram para cursos de bacharelado, pois são tratados como alunos de segunda categoria pelos professores e pelos colegas bacharelandos - ouvem coisas do tipo: "quem não sabe ou não tem competência para fazer pesquisa, vai ser professor". De forma um tanto simplificada, podemos dizer que um dos motivos centrais para a licenciatura estar em segundo plano ocorreu, por um lado, pelo o apoio à formação de novos pesquisadores - por meio das bolsas de iniciação científica - e, por outro lado, pela falta de apoio à formação de novos professores até meados da década de 90 (SAVIANI, 2009).

Obviamente, não estamos defendendo aqui uma formação de professores (um currículo de formação) que não valorize a pesquisa. Defendemos, sim, um professor que possa ser melhor formado não em oposição à pesquisa, mas com a pesquisa. Também não defendemos uma licenciatura em oposição ao bacharelado, mas uma licenciatura igualmente valorizada. Especialmente porque o tipo de alunado a entrar nas licenciaturas precisa de um investimento muito específico, 
provavelmente não sendo a pesquisa o primeiro aspecto mais importante.

\subsection{Terceira questão: um novo tipo de aluno está chegando às licenciaturas}

Pesquisas no campo da educação estabeleceram "há muito tempo [que] os resultados de uma escola dependem muito do tipo de aluno que atendem" (SOARES, 2007, p. 9) ou recebem. Partindo desse princípio e levando em conta que o público central dos cursos de licenciatura é oriundo de instituições públicas e das camadas populares, como lidar com esse alunado? Essa é uma questão central para uma mentalidade de governo contemporânea. Isso nos remete a alguns aspectos: a) entendendo a educação (de qualidade) como um potente mecanismo de conduta da conduta, talvez o principal; b) problematizando a racionalidade de governo neoliberal para uma conduta que busque e contemple eficiência, produção e economia, é possível deduzir que; c) há algo descompassado entre a lógica a nos perpassar (como formadores de novos seres humanos) e a perpassar o Estado e as técnicas e procedimentos para efetivá-las.

O primeiro desses descompassos talvez seja a fragilidade no domínio de conteúdo oferecido na educação básica pública, reafirmada pela fragilidade no domínio de outros componentes do conhecimento profissional tratados na formação inicial, tanto em instituições públicas como privadas. Conteúdos que deveriam ser adquiridos durante a trajetória escolar básica, não estão sendo. Surgem daí dois problemas. De um lado, não podemos negar que os alunos das licenciaturas estão, cada vez mais, chegando com déficit de formação em relação à língua culta, ao conhecimento científico e ao pensamento lógico matemático. De outro, precisamos discutir a reorganização dos cursos de formação, para que não se tornem apenas um espaço compensatório de déficits deixados pela educação básica (GATTI; SÁ BARRETO, 2009).

Dentre os descompassos, estão os conhecimentos da escrita que são percebidos nas produções dos estudantes. No ENEM, as questões abertas demonstram isso. Quando então falamos de questões políticas, as dificuldades de nossos alunos se multiplicam. O Golpe Militar e os Governos Ditatoriais dos anos 60 e 70 não fazem parte de seus mundos. 
Suas dificuldades são tantas que algumas pesquisas mostram que nem mesmo os cursos de formação estão conseguindo preencher as lacunas deixadas pela trajetória escolar anterior. Com isso, nos defrontamos com uma situação que precisa ser encarada: provavelmente muitos alunos e alunas irão atuar como professores, desconhecendo grande parte daquilo a ensinar e como deverão ensinar, com a devida profundidade teórica e metodológica (NONO; MIZUKAMI, 2001).

Outra faceta da questão é a necessidade de manutenção econômica e material desses alunos. Dados do Questionário Socioeconômico ENADE 2005 demonstram que 39,2\% dos licenciandos têm renda familiar de até três salários mínimos e 50,4\% de três a dez salários mínimos, diferentemente de informações anteriores que mostravam "uma categoria profissional relativamente homogênea, proveniente, em larga medida, dos estratos médios da população" (GATTI; SÁ BARRETO, 2009). Os mesmos dados mostram que $78 \%$ deles trabalham ou trabalharam durante a licenciatura, tendo uma carga horária de trabalho elevada (64,3\% de 20 a 40 horas ou mais de 40 horas). Fica-nos uma questão: como conciliar uma formação de qualidade (tão necessária à evolução da educação brasileira e a conduta da conduta para uma sociedade mais igualitária) para alunos que chegam com déficit de conhecimento e, ao mesmo tempo, precisam trabalhar?

Tudo aquilo descrito nas terceira e quarta seções deste texto evidencia "que a dificuldade de os alunos manterem o seu sustento durante a graduação" - além da dificuldade de tratar com os conteúdos acadêmicos -, somados à "baixa expectativa de renda em relação à futura profissão e o declínio do status social da docência fazem com que os cursos de licenciatura, tanto em instituições públicas como privadas, vivam em constante crise" (MARQUES; PEREIRA, 2002, p. 175). Em certa medida, vemos em xeque determinada mentalidade de governo que nos perpassa, pelo menos no que trate da formação inicial de professores. Questões sobre o lugar ocupado pelas licenciaturas e o novo tipo de alunado a ingressar nessa modalidade não são abordadas de frente pelas políticas de formação de professores contemporâneas. E elas parecem se acentuar quando observamos as relações existentes entre Ensino Superior e escolas públicas. 


\subsection{Quarta questão: aproximação entre instituições de ensino superior / escolas públicas municipais e estaduais}

Partimos do princípio que produzimos conhecimento na universidade para o implementar nas escolas, muitas vezes desconsiderando os saberes e as experiências dos professores que nelas se encontram. Consideramos, de certa maneira, que estamos no lugar de conduzir a conduta de outros, inclusive de outros professores que estão nas escolas. Ignoramos "que o conhecimento sempre deve estar inserido em um contexto socialmente estruturado, compartilhado pela comunidade dos praticantes [...]" (CUNHA, 2002, p. 41, grifos do autor). Esquecemos que a realidade é multifacetada e que cada escola e grupo de professores têm de vencer seus próprios desafios por meio de diferentes formas de ação a serem consideradas também como uma ação do governo de si. Os espaços e momentos que temos com as escolas (estágios, palestras, oficinas que oferecemos) são constituídos por complexas relações de poder (conduta da conduta de si, de outros e de Estado), no qual a formação inicial e continuada, o trabalho com a comunidade escolar e a prática de pesquisa talvez sejam pontos a se aproximarem e se complementarem.

Muitas vezes, como professores universitários, pesquisadores ou mesmo intelectuais, nos colocamos dentro do nosso "próprio discurso" enquanto revelamos "uma determinada verdade", descobrindo "relações políticas [e científicas] onde normalmente elas não [são supostamente] percebidas" (FOUCAULT; DELEUZE, 1996, p. 42) por outros. Esse lugar de distanciamento, ou pior, de superioridade em relação ao trabalho daqueles que estão no cotidiano não vem ajudando muito. Sem sombra de dúvida, devemos pensar (juntos) os problemas da escola, pesquisá-los como questões de todos nós, não como resultado de mentes brilhantes que enxergam diferenciadamente.

Parece-nos que não podemos mais levar nossas atividades prontas para as escolas desconsiderando o contexto no qual elas devem ser inseridas. Dificilmente diagnosticamos o cenário no qual estamos propondo algo. É como se antecipadamente soubéssemos das necessidades das escolas e como melhor nelas interferir. Observamos que "a falta de projetos 
que fortaleçam os vínculos entre a educação superior nas instituições formadoras de professores e as instituições de educação básica, para que haja trocas entre a universidade e a escola, parece tornar a formação inicial muito teórica e pouco realista" (BARCELOS; VILLANI, 2006, p. 74), além de abstrata, com certo tom totalitário. O entendimento da noção de intelectual a propor pelo outro, pois supõe saber das necessidades do outro, prevalece.

Para facilitar a articulação tão necessária entre instituições da educação básica e do ensino superior - partindo do princípio que as técnicas de dominação e as técnicas de si convivem na arte de governar -, deveríamos construir sondagens junto a professores e alunos visando à identificação de pontos conflitantes e obstáculos encontrados no ensino e na aprendizagem das áreas que realizam estágios e outras atividades nas escolas públicas. Nesse sentido, contar com a participação e o auxílio da direção e dos profissionais de cada escola são aspectos imprescindíveis. Seria interessante levantarmos as demandas específicas para construirmos e implementarmos ações estratégicas que promovam e incentivem a prática docente de nossos licenciandos, o aprimoramento dos professores das escolas nas quais desenvolvemos projetos de estágio, de extensão e de pesquisa.

Nosso sonho/nossa tensão é

tornar a formação inicial de professores um efetivo projeto coletivo, capaz de envolver a instituição formadora e o conjunto de formadores, e estabelecer uma parceria com a escola, na qual estagiários, professores e supervisores de estágio, juntos, possam aprender a trabalhar profissionalmente no cotidiano escolar. Certamente, pôr em prática estas diretrizes não será simples, sendo bem vindas as tentativas realizadas a esse respeito. (BARCELOS; VILLANI, 2006, p. 74)

Mesmo com isso, o paraíso não estará garantido. Demandará dos profissionais formadores investimento e tempo. Não imaginamos superar com isso "uma política de sociedade" pautada na conduta da conduta, e nem mesmo "um intervencionismo social, ao mesmo tempo ativo, múltiplo, vigilante e onipresente" (FOUCAULT, 2008b, p. 221) das formas de governar contemporâneas. Não temos essa ilusão. O intuito é pensar 
outras formas de governo de si e de outros menos pautadas no lugar do intelectual universitário e mais pautadas na construção coletiva. Além de deslocamentos dos lugares que supostamente ocupam como intelectuais, abordar os artefatos educacionais, especialmente o trabalho coletivo no currículo de formação, parece-nos de fulcral importância para tal coisa.

\subsection{Quinta questão: a organização do currículo de formação}

Trabalhos apontam para a dificuldade de integração entre as disciplinas dos currículos de formação. A estrutura universitária parece ser a principal responsável por isso, pois sua divisão em unidades e departamentos facilita o aparecimento de posições individuais entre os professores, impedindo, assim, aproximações e discussões em conjunto para construir e implantar um currículo mais articulado. A disciplina se torna "propriedade" do professor, e não parte integrante de uma maneira de funcionar do currículo do curso, havendo uma excessiva centralização na figura do docente em detrimento do conhecimento e/ou de uma proposta de formação a ser oferecida pelo curso ao longo de seu percurso. Em consequência, os professores não conseguem se aproximar para conversar sobre problemas como superposição de conteúdos, relação dos diferentes conteúdos entre si e significado desses no dia a dia dos alunos, causando deficiências em suas formações (MENDES, 1999).

Há outros aspectos a serem levados em conta. O primeiro é a relação hierarquizada e desconexa na formação do educador, estando pautada na própria organização curricular encontrada na maioria dos cursos de licenciatura, separando-os em etapas. As disciplinas da primeira etapa seriam as "teóricas" e supostamente mais difíceis e as estudadas na segunda etapa as "pedagógicas" ou as "práticas". Talvez isso desemboque na falta de compreensão da complexidade do cotidiano escolar, presente nesses currículos (GUERRA, 2000). Evidencia-se que a "pouca articulação entre as várias atividades que constituem o currículo de formação dos licenciandos na universidade parece minar a possibilidade" (BARCELOS; VILLANI, 2006, p. 74) de empregá-lo como um artefato não apenas controlador da vida do alunado, mas também 
como algo constituidor de uma formação consistente.

Moreira e Silva (1994) lembram que o currículo já há muito tempo deixou de ser um campo de indagações meramente técnicas nas quais as preocupações consistiam em "como" elaborá-lo de forma mais eficiente. Atualmente, a compreensão dos "motivos" a levarem a essa ou àquela configuração curricular se refere a pontos-chave nos estudos do campo do currículo. Várias relações são enfoques centrais de pesquisa no campo do currículo: gênero, sexualidade, relações étnico-raciais, tecnologias da informação e da comunicação etc. Segundo os mesmos autores, "nessa perspectiva, o currículo é considerado um artefato social e cultural. Isso significa que ele é colocado na moldura mais ampla de suas determinações sociais, de sua história, de sua produção contextual" (MOREIRA; SILVA, 1994, p. 7) sobre esses e outros enfoques.

Para entendermos melhor sua produção contextual, trazemos aqui algumas dimensões em relação ao currículo, explorando aspectos nos quais podemos interferir para a produção dos cursos de licenciatura: currículo oficial, currículo formal e currículo em ação. O currículo oficial é aquele proposto por órgãos oficiais de Estado, servindo como base para os currículos das instituições de ensino ${ }^{5}$. O currículo formal é aquele proposto pelas instituições de ensino e pelos docentes, a princípio, com base nas propostas oficiais. O currículo em ação é aquele praticado em sala de aula, em alguma medida, sob a influência das duas outras dimensões anteriores (PARAÍSO; SANTOS, 1996).

O currículo oficial e o currículo formal permitem certo controle sobre o trabalho e a formação docente, porém, são demasiadamente vagos e abstratos para definir a prática pedagógica no cotidiano escolar e de formação. Ambas as dimensões curriculares estão longe de ser suficientes para contemplar todas as nuances da dinâmica em sala de aula. Por mais pormenorizadas que sejam, o professor acaba organizando o seu trabalho cotidiano com base na trama produzida no seu cotidiano institucional. Isso, no entanto, demanda do docente a mobilização de um repertório de saberes - tratados na formação acadêmica, na formação

5 No caso das licenciaturas, as Diretrizes Curriculares Nacionais para a Formação de Professores: Resoluções CNE/CP n ${ }^{\circ}$ 01, de 18 de fevereiro de 2002, e CNE/CP n ${ }^{\circ}$ 02, de 19 de fevereiro de 2002. 
pedagógica, em relação ao domínio dos conteúdos a ensinar e avaliar etc. - no desenvolvimento desse trabalho.

Assim, ao se fazer o exercício na sala de aula entre o que consta nos currículos oficiais e formais para o currículo em ação, há um campo de manobra que leva em conta não apenas o que é prescrito, mas o que está subjacente. Dito de outra forma, existe uma parte obrigatória de interpretação, a qual o professor deve estar atento a fim de atender à demanda oficial. Não obstante, o conhecimento ensinado e avaliado é, em parte, criado e recriado no cotidiano escolar, tanto na preparação da aula quanto na dinâmica que se estabelece durante as atividades em sala de aula. Nesses movimentos, efetivamente, o professor contribui para a reinvenção dos saberes escolares e, nas licenciaturas, para a reinvenção da formação inicial.

A distância entre o que é proposto em currículos oficiais e formais e o que ocorre nos currículos em ação se explica por vários motivos. Aprender é uma atividade ao mesmo tempo individual e coletiva, requerendo desejo, disponibilidade e ação por parte do aluno ${ }^{6}$. Contribui para essa redefinição entre o que está na dimensão oficial e formal para a em ação vários aspectos, tais como a forma como as atividades de ensino são estruturadas, a dinâmica em sala de aula, a metodologia, a relação interpessoal e a comunicação estabelecida com os alunos, promovendo sua participação efetiva, entre outros.

O ensino não é unilateral. Pressupõe, de um lado, um professor imbuído de experiências, habilidades e um currículo a ser cumprido; de outro, alunos interessados ou desmotivados, unidos ou desunidos, disciplinados ou indisciplinados, preparados ou não na educação básica. Ainda temos as instituições de ensino com seus cronogramas, seus eventos e atividades. Tudo isso pode fugir, a princípio, ao controle e ao planejamento do professor. Não é à toa que sua sensibilidade com

6 Dentro de uma longa tradição, inspirada em Aristóteles e estabelecida por Tomás de Aquino para o campo educacional, pensamos a educação com seus dois grandes processos: o ensino e a aprendizagem. Partindo das noções de ato e potência em Aristóteles, Aquino afirma que o ensino é o ato que o professor promove, potencializando a aprendizagem do aluno. Nesse sentido, a aprendizagem estará em potência, como uma força que precisa de um empurrão para funcionar. Contudo, só funcionará com o interesse e a participação do aluno (ou aprendiz). Dito de outra maneira, educar só seria possível pelo ato de alguém que já aprendeu (ou domina ou mesmo detém) um saber, agindo consciente e de maneira planejada sobre outro alguém que potencialmente poderá (e quer) aprender. 
o funcionamento cotidiano se faz tão importante. Nesses casos, parece não ter tanta repercussão a promoção de mecanismos que facilitam a reprodução das propostas curriculares, mas sim a promoção de currículos que estimulem um trabalho docente diversificado em seus métodos e focados em seus objetivos em sala de aula, em todos os níveis de ensino.

Alguns detalhes podem ser percebidos nas entrelinhas do trabalho docente: existem experiências vividas em aula que não são perfeitamente conscientes; mesmo com a mediação do professor, as atividades raramente são executadas exatamente como planejadas. Com tudo isso, os professores precisam ser preparados para interpretar o currículo oficial e o formal, sem deixar de lado as relações de ensino e aprendizagem que se desenrolam no currículo em ação. À parte obrigatória de interpretação se junta a parte possível de criação.

O nosso argumento é de que a formação docente deveria preparar os professores para trabalharem métodos que possibilitem preparar aulas minimamente eficazes, levando em conta as três dimensões. Nossa eficácia na formação em sala de aula é construída atrelada à vivência com os alunos e suas realidades. Nessa direção, o intercâmbio com os colegas pode colaborar, igualmente, para o crescimento profissional de cada um de nós, ajudando-nos a tratar o currículo de forma crítica e coletiva. Por tudo isso, o conteúdo efetivo está longe de ser, a priori, completamente definido pelos currículos oficiais e formais. Por isso mesmo, outra questão primordial para a formação inicial de professores é o investimento proposto por políticas educacionais.

\subsection{Sexta questão: investimentos na formação inicial}

O cenário descrito nas seções anteriores evidencia o quanto as licenciaturas precisam de investimento e pesquisa. Somado a isso, parece-nos, cada vez mais, clarear "que nenhum dos fatores" de formação docente, quando abordados "de forma isolada, melhora[m] significativamente a qualidade do trabalho docente" (CAMPOS, 2006, p. 202). Não temos dúvida que "as instituições formadoras tem um alto grau de responsabilidade nas práticas pedagógicas dos professores e 
nas formas como se inserem" em seu trabalho (CAMPOS, 2006, p. 192). Contudo, apenas recentemente essas instituições formadoras têm sido estimuladas (pressionadas?) financeiramente a investir na formação inicial de maneira séria e regular.

O Programa de Licenciaturas (PROLICEN), lançado pela Secretaria do Ensino Superior (SeSu/MEC) em 1994, promoveu o primeiro apoio concreto e contemporâneo às licenciaturas, com bolsas Pró-Licenciatura para estimular os alunos a viverem intensamente a docência no espaço escolar, como ocorria com aqueles que tinham bolsas de iniciação científica para viverem a pesquisa. Infelizmente, o PROLICEN durou apenas dois anos. Mesmo assim, a partir de 1996, várias universidades institucionalizaram a iniciativa e a tornaram um programa interno. Podemos citar, com maior repercussão institucional, as seguintes: UFSC, UFG, UFPB, UFRGS, UFGD e UFCG (em 1994 era o campus II da UFPB). É importante ressaltar que, em todas elas, o PROLICEN (ou a ação que dele resultou) foi mantido até recentemente com recursos próprios das instituições.

Com a necessidade de se investir na formação de professores, no intuito de melhorá-la, talvez inspirado no PROLICEN e nos programas de iniciação científica, em 2007, foi lançado o Programa Institucional de Bolsa de Iniciação à Docência (PIBID/CAPES) - visando ao incentivo à docência dos estudantes das licenciaturas nas IFES e CEFETs. Em sua primeira edição - com edital de demanda contínua, ficando aberto do início de 2007 até 31 de dezembro de 2008 - foram contemplados 43 projetos em todo Brasil, disponibilizando R \$ 39 milhões. Entre os meses de setembro a dezembro de 2009, um segundo edital foi lançado pela CAPES, contemplando aproximadamente outros 100 projetos - nesse cenário, aceitando-se também projetos de Universidades Públicas Estaduais -, ofertando o montante de, aproximadamente, R \$ 225 milhões. De 13 de abril a 14 de maio esteve aberto o edital 018/2010/CAPES/ PIBID, dessa vez orientado apenas para instituições públicas municipais de educação superior e de universidades e centros universitários filantrópicos, confessionais e comunitários, sem fins lucrativos, não sendo divulgado o montante de verbas e agraciando 28 instituições. 
Entendemos que o PIBID - visando ao incentivo à docência dos estudantes das licenciaturas - chega em um momento oportuno para a formação inicial no Brasil.

Como relata Mendes (1999), apenas a formação em sala de aula não é suficiente para o exercício da profissão. A insegurança em relação à situação inicial da profissão docente tende a aumentar na medida em que o professor iniciante percebe que somente o aprendizado adquirido em sala de aula não foi suficiente. A própria sociedade nota que somente o acesso à escola não é o bastante para garantir o acesso ao saber, não só para o aluno da educação básica, mas também para aqueles que serão futuros professores. Sendo assim, o contato com professores a atuarem profissionalmente é importante, uma vez que proporciona um acompanhamento aos licenciandos (PERRENOUD, 2005). Dessa maneira, nota-se a importância de programas de iniciação para a docência, como aqueles estimulados pelo PIBID.

No contexto das universidades brasileiras, o PIBID pode ser visto como uma estratégia a amenizar os possíveis obstáculos que poderão ser enfrentados pelos futuros professores, alunos das licenciaturas, pois oferece apoio e orientação, na perspectiva de promover a aprendizagem e o desenvolvimento profissional. Nessa direção, para pensar sobre complexos assuntos morais e éticos relacionados à profissão docente, é importante que os discentes, dentre outras coisas, tenham experiências consistentes de sala de aula e de escola básica, antes de assumir a profissão e a própria sala de aula e a escola (PEREIRA; ZEICHNER, 2002).

\section{Concluindo}

Sabemos que a educação, já há algum tempo, é problematizada de forma relacional com a política. Isso implica vê-la como um território de relações de poder em torno do qual são travadas lutas, disputas e alianças. De fato, os processos de formulação, implementação e avaliação das políticas educacionais funcionam como arenas de disputas, nas quais se apresentam interesses diversos em luta por conquistar maior espaço e interferência política na definição de suas diretrizes, seus rumos e seus 
objetivos. De igual maneira, tais processos são frutos de prolongadas discussões e debates, nos mais diversos espaços: nas universidades, nas entidades de classes, em fóruns, nos movimentos sociais organizados, nas câmaras legislativas, nos conselhos consultivos etc. Sem dúvida, a política de formação de professores faz parte desse cenário.

Nesse complexo movimento, os direitos sociais tomam forma. A educação (e suas políticas), a saúde, o trabalho, a moradia, o lazer, a segurança, a previdência social, a proteção à maternidade e à infância e a assistência aos desempregados são direitos consagrados na Constituição. Entretanto, a definição de cada um deles é um processo construído em espaços políticos e de poder formais, somado com a possibilidade de intervenção individual do cidadão e também da sociedade civil organizada que, igualmente, são mudados ao intervir.

Toda essa discussão em torno da formação inicial de professores nos faz refletir sobre a finalidade de nossas instituições, nos forçando a levantar a seguinte pergunta: quais tipos de cidadãos e profissionais pretendemos formar e ser? Nesse sentido, ao investirmos em mudanças na licenciatura, sabemos que elas não ficarão restritas apenas à dimensão pedagógica. Elas trazem questões de caráter epistemológico e discursivo e se fazem necessárias discussões com os docentes universitários para a maior clareza sobre o significado que tais mudanças trazem, relacionando-as com o compromisso educacional de cada instituição e de cada profissional.

Acreditamos também que tais mudanças estão participando da constituição de alunos e professores, tanto na universidade como nas escolas públicas. Nessa direção, as discussões aqui presentes foram elaboradas com base na perspectiva de que o sujeito é da ordem da produção dos outros sobre ele e dele sobre ele mesmo. O sujeito é um produto - e, ao mesmo tempo, produtor - das práticas sociais, entendidas como aquelas conexões que nos ligam a outros humanos, a saberes e a relações de poder que nos rodeiam, constituindo a nós como tipos específicos de alunos e professores (FOUCAULT, 2008a). 


\section{Referências}

BARCELOS, N. N. S.; VILLANI, A. Troca entre universidade e escola na formação docente: uma experiência de formação inicial e continuada. Ciência \& Educação, v. 12, n. 1, p. 73-97, abr. 2006.

BRASIL. Resolução CNE/CP n. 1, de 30 de setembro de 1999. Dispõe sobre os Institutos Superiores de Educação. Diário Oficial da União, Brasília, 7 out. 1999.

BRASIL. Lei n. 9394, de 20 de dezembro de 1996. Estabelece as diretrizes e bases da educação nacional. Diário Oficial União, Brasília, 23 dez. 1996.

BRASIL. Resolução CNE/CP n. 1, de 18 de fevereiro de 2002. Institui Diretrizes Curriculares Nacionais para a Formação de Professores da Educação Básica, em nível superior, curso de licenciatura, de graduação plena. Diário Oficial da União, Brasília, 09 abr. 2002.

BRASIL. Resolução CNE/CP n. 2, de 19 de fevereiro de 2002. Institui a duração e a carga horária dos cursos de licenciatura, de graduação plena, de formação de professores da Educação Básica em nível superior. Diário Oficial da União, Brasília, 04 mar. 2002.

BRASIL. Lei n. 11.502, de 11 de julho de 2007. Modifica as competências e a estrutura organizacional da fundação Coordenação de aperfeiçoamento de Pessoal de Nível Superior - CAPES. Diário Oficial da União, Brasília, 12 jul. 2007.

BRASIL. Decreto n. 7.692, 02 de março de 2012. Aprova o Estatuto e o Quadro Demonstrativo dos Cargos em Comissão da fundação Coordenação de aperfeiçoamento de Pessoal de Nível Superior CAPES. Diário Oficial da União, Brasília, 6 mar. 2012. 
BRESSER-PEREIRA, L. C. A Reforma Gerencial do Estado de 1995. In: ANAIS DO SEMINÁRIO “MODERNA GESTÃO PÚBLICA”. Lisboa, 30-31 de março, 2000.

CAMPOS, M. R. Ator ou protagonista? Dilemas e responsabilidades sociais da profissão docente. In: CALDERANO, M. da A.; LOPES, P. R. C. (Orgs.). Formação de professores no mundo contemporâneo. Juiz de fora: Editora UFJF, 2006. p. 177-190.

CUNHA, M. I. Impactos das políticas de avaliação externa na configuração docente. In: ROSA, D. E. G.; SOUZA, V. C. (Orgs.). Políticas organizativas e curriculares, educação inclusiva e formação de professores. Rio de Janeiro/Goiânia: DP\&A/Alternativa, 2002. p. 39-56.

ESTEVES, M. Promover a racionalidade crítica na intervenção curricular dos professores. In: SANTOS, L. L. C. P.; FAVACHO, A. M. P. (Orgs.). Políticas e práticas curriculares. Curitiba: CRV, 2012. p. 21-34.

FOUCAULT, M. Ditos e escritos. Ética, sexualidade, política. Rio de Janeiro: Forense Universitária, 2004.

FOUCAULT, M. Segurança, território, população: curso dado no collège de france (1977-1978). São Paulo: Martins Fontes, 2008a.

FOUCAULT, M. Nascimento da biopolítica: curso dado no collège de france (1978-1979). São Paulo: Martins Fontes, 2008b.

FOUCAULT, M.; DELEUZE, G. O intelectual e o poder. In:

MACHADO, R. (Org.). Microfísica do poder. Rio de Janeiro: Graal, 1996. p. 41-45.

FREITAS, H. C. L. de. A (nova) política de formação de professores: a prioridade postergada. Educação \& Sociedade, v. 28, n. 100, p. 1.2031.230, out. 2007. Disponível em: <http:/ /www.scielo.br/pdf/es/ 
v28n100/a2628100.pdf >. Acesso em: 02 set. 2013.

GATTI, B A.; SÁ BARRETTO, E. S. Professores do Brasil: impasses e desafios. Brasília: UNESCO, 2009.

GOZZI, G. Estado contemporâneo. In: BOBBIO, N.; MATTEUCCI, N.; PASQUINO, G. (Orgs.). Dicionário de política. Brasília: UNB, 1998. p. 401-409.

GUERRA, M. D. S. Reflexões sobre um processo vivido em estágio supervisionado: dos limites a possibilidades. In: REUNIÃO ANUAL DA ANPED 23. Caxambu, 2000. Anais eletrônicos... Disponível em: <http://23reuniao.anped.org.br/textos/0839t.PDF>. Acesso em: 16 jan. 2010.

LEVI, L. Governo. In: BOBBIO, N.; MATTEUCCI, N.; PASQUINO, G. (Orgs.). Dicionário de política. Brasília: UNB, 1998. p. 553-555.

LIBÂNEO, J. C. Alguns aspectos da política educacional do governo Lula e sua repercussão no funcionamento das escolas. Revista HISTEDBR On-line, Campinas, n. 32, p. 168-178, dez. 2008.

LIMA, E. F. de. Passado, presente e futuro do curso de pedagogia. In: MACIEL, L.; NETO, A. (Orgs.). Formação de professores: passado, presente e futuro. São Paulo: Cortez, 2004. p. 21-42.

MACIEL, L.; NETO, A. Formação de professores: passado, presente e futuro. São Paulo: Cortez, 2004.

MALANCHEN, J.; VIEIRA, S. da R. A política brasileira de formação de professores: repercussões sobre o trabalho docente. In: SEMINÁRIO DA REDESTRADO, 6. Rio de Janeiro: UERJ, 2006.

MARQUES, C. A.; PEREIRA, J. E. D. Fóruns das licenciaturas em 
universidades brasileiras: construindo alternativas para a formação inicial de professores. Educação \& Sociedade, ano 23, n. 78, abr. 2002.

MENDES, C. L. A reforma curricular do curso de educação física da UFMG: relações de poder, atores e seus discursos. 1999. 154 f. Dissertação (Mestrado) - Faculdade de Educação, Universidade Federal de Minas Gerais, Belo Horizonte, 1999.

MOREIRA, A. F. B.; SILVA, T. T. Sociologia crítica do currículo. In: . Currículo, cultura e sociedade. São Paulo: Cortez, 1994. p. 7-39

NONO, M. A.; MIZUKAMI, M. da G. Aprendendo a ensinar: futuras professoras das séries iniciais do ensino fundamental e casos de ensino. In: REUNIÃO ANUAL DA ANPED, 24. Caxambu, 2001. Anais eletrônicos... Disponível em: <http:/ / 24reuniao.anped.org.br/ tp.htm\#gt8>. Acesso em: 25 jan. 2013.

OLIVEIRA, D. A. As políticas educacionais no governo Lula: rupturas e permanências. Revista Brasileira de Política e Administração da Educação, v. 25, n. 2, p. 197-209, mai./ago. 2009.

PARAÍSO, M. A.; SANTOS, L. L. C. P. O currículo como campo de luta. Presença Pedagógica, v. 2, n. 7, p. 32-39, jan./fev. 1996.

PEREIRA, J.; ZEICHNER, K. M. A pesquisa na formação e no trabalho docente. Belo Horizonte: Autêntica, 2002.

PERRENOUD, P. A escola de a a z: 26 maneiras de repensar a educação. Porto Alegre. Artmed. 2005.

PRUDENTE, P. L. G. O currículo dos cursos de educação física: para além do senso comum. 2009. 123 f. Dissertação (Mestrado) - Fundação Universidade de Itaúna, 2009. 
REALI, A.; FERREIRA, L. Aprendendo a ensinar e a ser professor: contribuições e desafios de um programa de Iniciação a docência para professores de educação física. In: REUNIÃO ANUAL DA ANPED, 28. Caxambu, 2005. Anais eletrônicos... Disponível em: <http:/ / 28reuniao.anped.org.br/textos/gt08/gt08183int.rtf >. Acesso em: 25 jan. 2013.

RABINOW, P.; ROSE, N. O conceito de biopoder hoje. Política e Trabalho, n. 24, abr. 2006, p. 27-57.

SANTOS, L. L. C. P. Ensino como produção cultural: novas perspectivas para o currículo e a formação de professores. In: LEITE, D. B. C.; MOROSINI, M. (Orgs.). Universidade futurante. Campinas: Papirus, 1997. p. 63-74.

SAVIANI, D. Formação de professores: aspectos históricos e teóricos do problema no contexto brasileiro. Revista Brasileira de Educação, v. 14, n. 40 jan./abr. 2009. Disponível em: <http:/ / www.scielo.br/pdf/ rbedu/v14n40/v14n40a12.pdf >. Acesso: 20 set. 2013.

SEVERINO, A. J. Metodologia do trabalho científico. São Paulo: Cortez, 2008.

SOARES, J. F. A avaliação educacional e a formação docente. In:

SOUZA, J. V. A. (Org.). Formação de professores para a educação básica. Belo Horizonte: Autêntica, 2007. 